Check for updates

Cite this: RSC Adv., 2017, 7, 47913

Received 6th August 2017

Accepted 7th October 2017

DOI: $10.1039 / \mathrm{c} 7 \mathrm{ra0} 8695 \mathrm{~d}$

rsc.li/rsc-advances

\section{Study of the relationship between magnetic field and dielectric properties in two ferromagnetic complexes $\uparrow$}

\author{
Li Yang, ${ }^{a}$ Jing Li, ${ }^{a}$ Tian-Cheng Pu, ${ }^{b}$ Ming Kong, ${ }^{a}$ Jing Zhang ${ }^{a}$ and You Song (D) *a \\ By changing metal ions in the existing [guest] $\left[\mathrm{M}^{\prime \prime \prime} \mathrm{M}^{\prime \prime}(\mathrm{HCOO})_{6}\right]$ framework, heterometallic formate \\ frameworks formulated as $\left[\mathrm{NH}_{2}\left(\mathrm{CH}_{3}\right)_{2}\right]\left[\mathrm{Cr}{ }^{\prime \prime \prime} \mathrm{Fe}{ }^{\prime \prime}(\mathrm{HCOO})_{6}\right]$ (1) and $\left[\mathrm{NH}_{2}\left(\mathrm{CH}_{3}\right)_{2}\right]\left[\mathrm{Cr}^{\prime \prime \prime} \mathrm{Ni}(\mathrm{HCOO})_{6}\right]$ (2) were \\ synthesized and characterized by single crystal $\mathrm{X}$-ray diffraction, dielectric measurement and magnetic \\ susceptibility measurement. Both complexes 1 and 2 exhibit long-range ferromagnetic ordering (LRO) at \\ Curie temperatures of 15.3 (1) and $20.9 \mathrm{~K}$ (2) through ac magnetization susceptibility and $\mathrm{zfc} / \mathrm{fC}$ \\ measurements. Complex 1 possesses a hysteresis loop with $H_{\mathrm{c}} / \mathrm{M}_{\mathrm{r}}$ being $2.77 \mathrm{kOe} / 2.83 \quad \mathrm{~N} \mu_{\mathrm{B}}$. \\ Measurements on the dielectric properties of 1 and 2 show an apparent dielectric response. Interestingly, \\ the dielectric constants can be increased under an applied magnetic field.
}

\section{Introduction}

Multiferroic materials, a family of recently emerged complexes which display both magnetic and ferroelectric ordering, have attracted significant research attention due to their promising applications in many electronic devices such as storage elements, sensors, etc. ${ }^{\mathbf{1 1 3}}$ Metal organic frameworks (MOFs) containing guest molecules or cations can be an excellent choice in the seeking of multiferroic materials. A typical class of these MOFs structurally resembles perovskite $\mathrm{ABO}_{3}$-type materials. ${ }^{1-6}$ Among this family of MOFs, metal formate frameworks are particularly interested since the $\mathrm{HCOO}^{-}$ion can mediate the ferro- or antiferromagnetic coupling between metal ions due to its small size. Their structures can be formulated as [\{guest molecule or cation\} $\left.\left\{(\text { metal ion)(formate })_{3}\right\}\right]$ and simplified as [guest $]\left[\mathrm{M}(\mathrm{HCOO})_{3}\right]^{1 \mathbf{1 4 - 2 1}}$ Many of these metal formate frameworks have been discovered with interesting magnetic properties and rich ferroelectricity. Xiong et al. investigated the deuteration effect in the system of PDDMACoF, where PD-DMA = perdeuterodimethylammonium. This complex was observed with second harmonic generation (SHG) effect below $151 \mathrm{~K}$, magnetic hysteresis at $5 \mathrm{~K}$ and a first reported phase transition above room temperature at $319 \mathrm{~K}^{22}$ Though the system of [guest $]\left[\mathrm{M}(\mathrm{HCOO})_{3}\right]$ frameworks with $\mathrm{M}=$ divalent

${ }^{a}$ State Key Laboratory of Coordination Chemistry, Collaborative Innovation Center of Advanced Microstructures, School of Chemistry and Chemical Engineering, Nanjing University, Nanjing 210093, China.E-mail: yousong@nju.edu.cn

${ }^{b}$ Department of Chemical and Biomolecular Engineering, John Hopkins University, Baltimore, Maryland 21218, USA

$\dagger$ Electronic supplementary information (ESI) available: Selected bond lengths and angles, magnetic characterizations, dielectric characterizations and X-ray crystallographic files in CIF format for 1 and 2. CCDC 1536009 for 1 and 1539328 for 2. For ESI and crystallographic data in CIF or other electronic format see DOI: $10.1039 / \mathrm{c} 7 \mathrm{ra08695d}$ cation has been extensively studied, the diversity in heterometallic and mixed-valence formate is still waiting to be discovered.

Several years ago, a mixed-valence iron(III)-iron(II) formate ([DMFeFe]) was discovered, which exhibits temperature compensation behaviour as Néel N-type ferrimagnet. ${ }^{23,24}$ DMFeFe crystallizes in the niccolite type structure with the disordered cations located in the cages of the network. Following such work, Bu et al. reported rare asymmetric magnetization reversal in hysteresis loop in the same DMFeFe complex. ${ }^{17}$ Moreover, some complexes with $\mathrm{ABO}_{3}$-type perovskite structure as well as chiral- and niccolite-type structures display sequential structural phase transitions, which give insight on application prospects of this family of complexes. ${ }^{2,12,25-38}$ On the other hand, dielectricity can be a quite important property of the complexes but only a few studies on the dielectricity for these mixed-valence formate frameworks were reported. ${ }^{30-33}$ Materials with high dielectric constant greater than that of silicon nitride $\left(\varepsilon^{\prime}>7\right)$ are excellent choices for high performance capacitors and insulators and still require further investigation..$^{39,40}$

Herein, in order to study formate frameworks as multifunctional materials, we have investigated the synthesis and characterization of the complexes: $\left[\mathrm{NH}_{2}\left(\mathrm{CH}_{3}\right)_{2}\right]$ $\left[\mathrm{Cr}^{\mathrm{III}} \mathrm{Fe}^{\mathrm{II}}(\mathrm{HCOO})_{6}\right]$ (1) and $\left[\mathrm{NH}_{2}\left(\mathrm{CH}_{3}\right)_{2}\right]\left[\mathrm{Cr}^{\mathrm{III}} \mathrm{Ni}^{\mathrm{II}}(\mathrm{HCOO})_{6}\right]$ (2), which exhibit ferromagnetic ordering. Complex 1 possesses a hysteresis loop with a large coercive field of 2.77 kOe. Two complexes display relatively high dielectric constants, stepwise temperature dependent behavior and obvious dielectric constants change under an applied magnetic field.

\section{Experimental}

\section{Materials and instrumentation}

All chemicals were commercially available and used as received without further purification. The $\mathrm{C}, \mathrm{H}, \mathrm{N}$ microanalyses were 
carried out with a PE 2400 series II elemental analyzer. The FTIR spectra was recorded from $\mathrm{KBr}$ pellets in the range of 4000$500 \mathrm{~cm}^{-1}$ on a PE spectrum one FT-IR spectrometer. The metal ions were calculated with the molar ratio which could be proved by Optima 5300 DV ICP-OES system. Dielectric permittivity measurements were collected on Broad Band Dielectric Spectrometer. The diameter of sample pellets for dielectric measurement is $6 \mathrm{~mm}$ and the thickness is $0.5 \mathrm{~mm}$. The crystal structure was determined by single-crystal X-ray diffraction and using SHELXS-97, SHELXL-97 software for structure solution and refinement, correspondingly. The data of magnetic properties for crystalline samples was collected on a Quantum Design MPMS-XL 7 superconducting quantum interference device (SQUID) magnetometer.

\section{Synthesis}

$\left[\mathbf{N H}_{2}\left(\mathbf{C H}_{3}\right)_{2}\right]\left[\mathrm{Cr}^{\mathrm{III}} \mathbf{F e}^{\mathrm{II}}(\mathbf{H C O O})_{6}\right]$ (1). A mixture of $\mathrm{CrCl}_{3} \cdot 6 \mathrm{H}_{2} \mathrm{O}$ $(0.5 \mathrm{mmol}), \mathrm{FeCl}_{2} \cdot 4 \mathrm{H}_{2} \mathrm{O}(0.5 \mathrm{mmol})$ in dimethylformamide (DMF) and formic acid (total $16 \mathrm{~mL}$ ) (v/v $1: 1$ ) was sealed in a Teflon-lined stainless steel vessel, heated at $140{ }^{\circ} \mathrm{C}$ for 120 hours under autogenous pressure, and then cooled to room temperature. Black-green crystals of 1 were harvested in about $\sim 68 \%$ yield based on metal salt. Anal. calc. for 1: $\mathrm{C}_{8} \mathrm{H}_{14}{ }^{-}$ $\mathrm{CrFeNO}_{12}\left(M_{\mathrm{r}}=424.04\right)$, calc.: $\mathrm{C}, 21.23 ; \mathrm{H}, 3.12 ; \mathrm{N}, 3.09 \%$; found: C, 21.58; H, 3.24; N, 3.28\%. ICP: Cr, 6.67; Fe, 7.38. Ratio of $\mathrm{Cr}: \mathrm{Fe}=1: 1.03$. IR data for $1\left(\mathrm{KBr}, \mathrm{cm}^{-1}\right): 3160 \mathrm{~m}, 1584 \mathrm{~s}$, 1342 s 1019 w, 823 s, 431 s (s, strong; m, medium; w, weak).

$\left[\mathbf{N H}_{2}\left(\mathrm{CH}_{3}\right)_{2}\right]\left[\mathbf{C r}^{\mathrm{III}} \mathbf{N i}^{\mathrm{II}}(\mathbf{H C O O})_{6}\right]$ (2). Complex 2 was synthesized in comparable yields by following procedures very similar to complexes 1 using $\mathrm{CrCl}_{3} \cdot 6 \mathrm{H}_{2} \mathrm{O}(0.5 \mathrm{mmol})$ and $\mathrm{NiCl}_{2} \cdot 6 \mathrm{H}_{2} \mathrm{O}$ $(0.5 \mathrm{mmol})$, as the metal ion source. Black-green crystals of 2 were harvested in about $\sim 53 \%$ yield based on metal salt. Anal. calc. for 2: $\mathrm{C}_{8} \mathrm{H}_{14} \mathrm{CrNiNO}_{12}\left(M_{\mathrm{r}}=426.89\right)$, calc.: C, 20.83; $\mathrm{H}$, 3.06; N, 3.04\%; found: C, 20.73; H, 3.19; N, 3.29\%. ICP: Cr, 12.51; Ni, 13.83. Ratio of $\mathrm{Cr}: \mathrm{Ni}=1: 0.98$. IR data for 2 $\left(\mathrm{KBr}, \mathrm{cm}^{-1}\right): 3160 \mathrm{~m}, 1584 \mathrm{~s}, 1342$ s 1019 w, 823 s, 431 s (s, strong; m, medium; w, weak).

\section{Crystal structure determination}

A suitable black-green block crystal with dimensions of $0.23 \mathrm{~mm}$ $\times 0.20 \mathrm{~mm} \times 0.16 \mathrm{~mm}$ for 1 and black-green block crystal with dimensions of $0.19 \mathrm{~mm} \times 0.18 \mathrm{~mm} \times 0.15 \mathrm{~mm}$ for 2 were mounted on a glass fiber and the data was collected on a Bruker Smart Apex CCD diffractometer with graphite monochromated Mo-K $\alpha$ radiation $(\lambda=0.71073 \AA)$. Using the $\omega-\theta$ scan mode in the range of $2.86^{\circ} \leq \theta \leq 27.49^{\circ}$ (1) and $2.88^{\circ} \leq \theta \leq 27.52^{\circ}$ (2). Raw frame data was integrated with the SAINT program. The structures were solved by direct methods using SHELXS-97 (ref. 41) and refined by full-matrix least-squares on $F^{2}$ using SHELXS97. ${ }^{42}$ An empirical absorption correction was applied with the program SADABS. ${ }^{43}$ All non-hydrogen atoms were refined anisotropically. All hydrogen atoms were positioned geometrically and refined as riding. Calculations and graphics were performed with SHELXTL. ${ }^{\mathbf{2}}$ The crystallographic details are provided in Table 1 . Selected bond distances and angles for $\mathbf{1}$ and $\mathbf{2}$ are listed in Tables S1 and $\mathrm{S} 2 . \dagger$ Crystallographic data for
Table 1 Crystallographic data for complexes 1 and 2

\begin{tabular}{|c|c|c|}
\hline Complex & 1 & 2 \\
\hline Mol. form. & $\mathrm{C}_{8} \mathrm{H}_{14} \mathrm{CrFeNO}_{12}$ & $\mathrm{C}_{8} \mathrm{H}_{14} \mathrm{CrNiNO}_{12}$ \\
\hline Form. weight & 424.04 & 426.89 \\
\hline$T / \mathrm{K}$ & $296(2)$ & $296(2)$ \\
\hline Color and form & Black, block & Black-green, block \\
\hline Crystal system & Trigonal & Trigonal \\
\hline Space group & $P \overline{3} 1 c(163)$ & $P \overline{3} 1 c(163)$ \\
\hline$a / \AA$ & $8.2353(4)$ & $8.1651(3)$ \\
\hline$b / \AA$ & $8.2353(4)$ & $8.1651(3)$ \\
\hline$c / \AA$ & $13.7385(13)$ & $13.5314(10)$ \\
\hline$\alpha /^{\circ}$ & 90.00 & 90.00 \\
\hline$\beta /^{\circ}$ & 90.00 & 90.00 \\
\hline$\gamma / /^{\circ}$ & 120.00 & 120.00 \\
\hline$V / \AA^{3}$ & $806.92(9)$ & $781.26(7)$ \\
\hline$Z$ & 2 & 2 \\
\hline$F(000)$ & 446 & 450 \\
\hline$D_{\text {calcd }} / \mathrm{g} \mathrm{cm}^{-3}$ & 1.836 & 1.908 \\
\hline$\mu / \mathrm{mm}^{-1}$ & 1.64 & 1.97 \\
\hline$\theta$ Range $/^{\circ}$ & 2.86 to 27.49 & 2.88 to 27.52 \\
\hline Ref. coll./unique & $6941 / 632$ & $6423 / 613$ \\
\hline$R_{\text {int }}$ & 0.0265 & 0.0314 \\
\hline Completeness & $99.8 \%$ & $100 \%$ \\
\hline Parameters & 40 & 40 \\
\hline GOF & 1.172 & 1.244 \\
\hline$R_{1}[I \geq 2 \sigma(I)]$ & 0.0282 & 0.0339 \\
\hline $\mathrm{w} R_{2}$ (all data) & 0.0913 & 0.0905 \\
\hline Residues/e $\AA^{-3}$ & 0.198 and -0.728 & 0.312 and -0.949 \\
\hline
\end{tabular}

the structural analysis have been deposited with the Cambridge Crystallographic Data Center (CCDC reference numbers: 1536009(1) and 1539328(2)).

\section{Results and discussion}

\section{Description of crystal structure}

Single-crystal X-ray structure analysis reveals that complex 1 crystallized in the trigonal space group $P \overline{3} 1 c$, as observed in many other metal formate series, ${ }^{17,18}$ which contains one unique $\eta^{2}$-formate anion that bridges two metal ions $\mathrm{Cr}^{\mathrm{III}}$ and $\mathrm{Fe}^{\mathrm{II}}$ to form a framework (Fig. 1a). The framework is similar to structures of niccolite NiAs and colquiriite $\mathrm{Li}-\mathrm{CaAlF}_{6} \cdot{ }^{44}$ The metal ions are all in octahedral environment coordinated by six oxygen atoms from six formate anions. The two inhomogeneous metal atoms in the asymmetric unit were distinguished by the bond lengths. The $\mathrm{Cr}^{\mathrm{III}}-\mathrm{O}$ bonds lengths in $\mathbf{1}$ are $1.9796 \AA$, meanwhile the $\mathrm{Fe}^{\mathrm{II}}-\mathrm{O}$ bonds lengths are $2.1174 \AA$. The assignment of $\mathrm{Cr}^{\mathrm{III}}$ and $\mathrm{Fe}^{\mathrm{II}}$ ion was supported by bond valence calculations. ${ }^{45,46}$ The three-dimensional structure (Fig. 1a) consists of two kinds of octahedral 6-connected metal nodes, $\left(4^{9} \cdot 6^{6}\right)$ and $\left(4^{12} \cdot 6^{3}\right)$ for $\mathrm{Cr} 1$ and Fe1, respectively, linked by antianti formate ligands. The $\mathrm{Me}_{2} \mathrm{NH}_{2}{ }^{+}$cations are located in cavities of the network. The Fe1 node is in a spatial arrangement of an octahedron (Fig. 1b), while the Cr1 node is in a spatial arrangement of trigonal prism (Fig. 1c). The framework is composed of waved sheets linked by intersheet formate bridges 


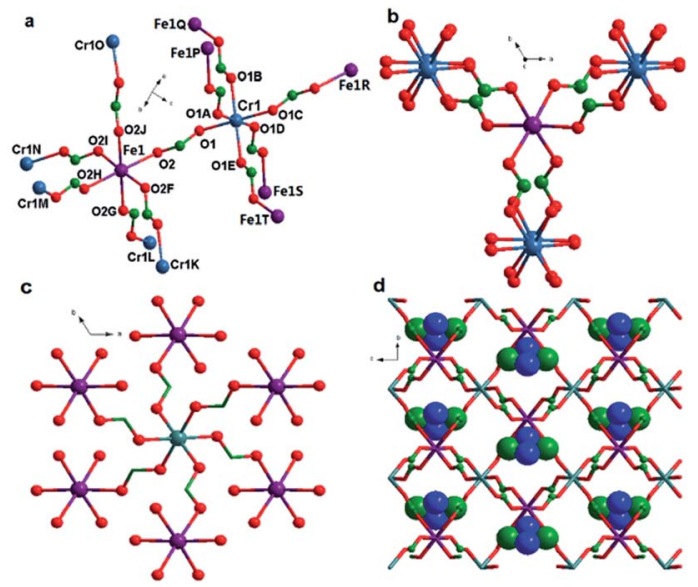

Fig. 1 (a) Coordination and linkage modes in the complexes. (b) The local coordination environment of the $\left(4^{12} \cdot 6^{3}\right)$ node, Fe1, and (c) that of the $\left(4^{9} \cdot 6^{6}\right)$ node, $\mathrm{Cr} 1$, viewed down the $c$ axis. Note the difference in the spatial arrangement of the neighboring $\mathrm{Cr}^{3+}$ and $\mathrm{Fe}^{2+}$ ions. (d) 3D space-filling view of the $\left[\mathrm{NH}_{2}\left(\mathrm{CH}_{3}\right)_{2}\right]\left[\mathrm{Cr} \mathrm{r}^{\prime \prime \prime} \mathrm{Fe} \mathrm{F}^{\prime \prime}(\mathrm{HCOO})_{6}\right]$ framework with the cations filled in the cavities.

(Fig. 1d). In the wavy sheet, $\mathrm{Cr} 1$ ions lie at the peaks and troughs while Fe1 ions are located in between.

In the framework, $\mathrm{Fe} 1$ links only $\mathrm{Cr} 2$ and vice versa. The unique formate-bridged $\mathrm{Cr} 1 \cdots \mathrm{Fe} 1$ distance is $5.865 \AA$.

The $\mathrm{MO}_{6}$ octahedron is distorted with cis $\mathrm{O}-\mathrm{Cr}-\mathrm{O}$ angles of 88.92-91.08 ${ }^{\circ}$, trans $\mathrm{O}-\mathrm{Cr}-\mathrm{O}$ angles of $180^{\circ}$, cis $\mathrm{O}-\mathrm{Fe}^{\mathrm{II}}-\mathrm{O}$ angles of $85.09-93.10^{\circ}$, and trans $\mathrm{O}-\mathrm{Fe}^{\mathrm{II}}-\mathrm{O}$ angles of $177.48-180.00^{\circ}$. Introducing $\mathrm{Fe}^{\mathrm{II}}$ ion does not change the basic construction of this kind of MOFs, so the interatomic distances of $\mathrm{M}-\mathrm{O}$ and $\mathbf{M} \cdots \mathbf{M}$ of $\mathbf{1}$ are in good agreement with those in the reported mixed-valence formate complexes. ${ }^{30}$ Complexes $\mathbf{1}$ and $\mathbf{2}$ are isostructural only with different $\mathrm{M}^{\mathrm{II}}$ ions. So herein, the structure of $\mathbf{2}$ is not described any more.

\section{Magnetic studies}

The plots of the temperature dependence of the magnetic susceptibilities of $\mathbf{1}$ and $\mathbf{2}$, measured under applied magnetic fields of 2000 Oe, are shown in Fig. 2 in the form of $\chi_{M} T$. The $\chi_{\mathrm{M}} T$ values at $300 \mathrm{~K}$ are 5.95 (1) and $3.08 \mathrm{~cm}^{3} \mathrm{~K} \mathrm{~mol}^{-1}$ (2), respectively. Among them, the $\chi_{\mathrm{M}} T$ value of the complex 2 was slightly higher than the spin-only value $2.875 \mathrm{~cm}^{3} \mathrm{~K} \mathrm{~mol}^{-1}$ of magnetically non-interacting chromium(III) $(S=3 / 2, g=2)$ and the nickel(II) $(S=1, g=2)$ metal ions. However, the $\chi_{\mathrm{M}} T$ value of complex 1 is much larger than the spin-only value $4.875 \mathrm{~cm}^{3} \mathrm{~K}$ $\mathrm{mol}^{-1}$ of spin-only chromium(III) $(S=3 / 2, g=2)$ and the isolated high-spin iron(II) $(S=2, g=2)$ with the orbital degeneracy and spin-orbit coupling effects contribute of the octahedral high-spin iron(II). . $^{14,15}$

The temperature dependence of reciprocal susceptibility $\chi_{\mathrm{M}}{ }^{-1}$ above $60 \mathrm{~K}$ follows the Curie-Weiss law $[\chi=C /(T-\theta)]$ (Fig. S1 and S2, ESI $\dagger$ ), giving Curie $\left(\mathrm{cm}^{3} \mathrm{~K} \mathrm{~mol}^{-1}\right) /$ Weiss (K) constants of: 5.98/0.33 (1) and 3.02/25.13 (2), without considering the spinorbit coupling contribution. The Curie constants can derive Land $g$ factors of 2.22 and 2.04 for $\mathbf{1}$ and 2 , respectively. The $g$ factor of 2 is in good agreement with isotropic $\mathrm{Ni}^{2+},{ }^{14-16}$ while that of $\mathbf{1}$ is

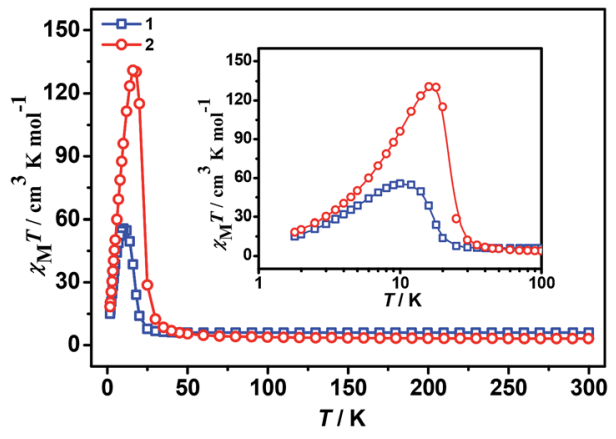

Fig. 2 Plots of $\chi_{M} T$ versus $T$ under 2000 Oe field. Inserted graph is the curve with $\chi_{M} T$ and $T$ axes are in logarithmic scale for easy observation of the variation in the low-temperature region for 1 and 2 .

slightly larger just for the spin-orbit coupling effect of the high spin $\mathrm{Fe}^{2+} \cdot{ }^{14,15}$ The significant positive Weiss constants show ferromagnetic exchange interactions between the nearestneighbor metal ions, and this is expected for an anti-anti mode of coordination by the formate bridges. ${ }^{17,18,47}$

The shape of two curves is similar but there are some differences between $\mathbf{1}$ and $\mathbf{2}$ due to the different metal ions. For 1, $\chi_{\mathrm{M}} T$ value first slowly increases from $300 \mathrm{~K}$ to $70 \mathrm{~K}$, then rapidly increases to the maximum of $55.68 \mathrm{~cm}^{3} \mathrm{~K} \mathrm{~mol}^{-1}$ at 10.01 $\mathrm{K}$ and decreased to $15.00 \mathrm{~cm}^{3} \mathrm{~K} \mathrm{~mol}^{-1}$ at $1.8 \mathrm{~K}$. For 2 , the $\chi_{\mathrm{M}} T$ value slowly increases from $300 \mathrm{~K}$ to $35 \mathrm{~K}$ and displays a sharp rise to a maximum of $130.76 \mathrm{~cm}^{3} \mathrm{~K} \mathrm{~mol}^{-1}$ at $16.00 \mathrm{~K}$, and then decreases to $18.33 \mathrm{~cm}^{3} \mathrm{~K} \mathrm{~mol}^{-1}$ at $1.8 \mathrm{~K}$. The maximum of $\chi_{\mathrm{M}} T$ value is much larger than that of $\mathbf{1}$ although the spin of carriers in $\mathbf{2}$ is lower than in $\mathbf{1}$, indicating complex $\mathbf{2}$ generates the larger magnetized domain. In the low-temperature region, the $\chi_{\mathrm{M}} T$ values of the two complexes rise up quickly to maxima, and finally go down upon cooling, thus suggesting the presence of spontaneous magnetization due to the magnetic long-range ordering (LRO). The sequence of the magnetic-ordering temperature is $\mathbf{1}<\mathbf{2}$.

All these observations are similar to the known metalformate perovskites. ${ }^{17,18}$ To confirm the conclusion above for the two complexes, we further measured the zero-field-cooling (zfc) and field-cooling (fc) magnetizations under a low magnetic field (Fig. 3), alternating current (ac) susceptibilities at $10 \mathrm{~Hz}$ for $\mathbf{1}, 1000 \mathrm{~Hz}$ for 2 (Fig. 4), and isothermal magnetizations (Fig. 5 and S3†). Under 1 Oe field (Fig. 3), the two curves of $\mathrm{zfc} / \mathrm{fc}$ are superposed at higher temperatures. They increase abruptly and then diverge indicating long-range magnetic ordering. The ordered temperatures, determined by the positions of the negative peak on the derivative $\mathrm{d} M / \mathrm{d} T(M=$ magnetization) of fc data, are 15.26 (1) and $20.93 \mathrm{~K}$ (2).

The temperature dependences of the ac susceptibilities obtained under zero direct current (dc) field (Fig. 4) for the two complexes. They all display peaks in both the in-phase $\left(\chi^{\prime}\right)$ and out-of-phase $\left(\chi^{\prime \prime}\right)$ responses. Frequency-independent peak in $\chi^{\prime \prime}$ were observed at $15.50 \mathrm{~K}$ for 1 . Complex 2 displays the weak ac responses but frequency-independent peak for $\chi^{\prime \prime}$ at $21.00 \mathrm{~K}$ was clear. Therefore, the ac studies confirmed the LRO of ferromagnetism of the two complexes. 


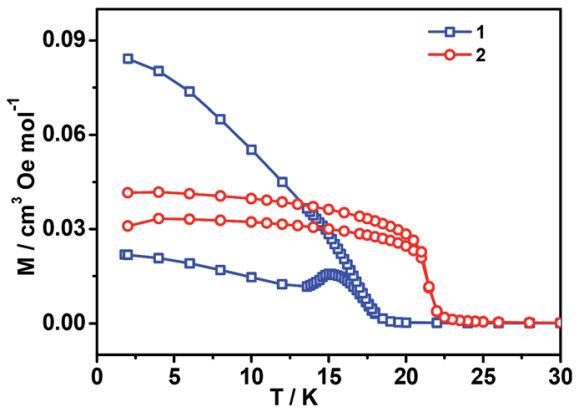

Fig. 3 The $\mathrm{zfc} / \mathrm{fc}$ plots of the two complexes under 1 Oe field.

The isothermal magnetizations at $2.0 \mathrm{~K}$ for $\mathbf{1}$ and 2 (Fig. 5 and S3) have been measured. Only 1 displays hysteresis loop with $H_{\mathrm{c}} / M_{\mathrm{r}}$ being $2.77 \mathrm{kOe} / 2.83 N \mu_{\mathrm{B}}$. In complex 1 , the magnetization sharply increases to $3.33 N \mu_{\mathrm{B}}$ in $8.42 \mathrm{kOe}$, and then slowly climbs up to $4.72 N \mu_{\mathrm{B}}$ in 70 kOe. Obviously, the magnetization does not reach saturation of $g\left(S_{\mathrm{Fe}}+S_{\mathrm{Cr}}\right)=2 \times(2+3 / 2)$ $=7 N \mu_{\mathrm{B}}$ even not considering the orbital contribution. According to the shape of curve, it is believed that there exists the strong magnetic anisotropy. Regrettably, we did not obtain the big enough single crystals for the physical measurement. Complex 2 is easier to be magnetized than 1. In low field, the magnetization of $\mathbf{1}$ suddenly increases and is immediately saturated at $4.91 N \mu_{\mathrm{B}}$ in $6.0 \mathrm{kOe}$. Above this field, the magnetization almost keeps a constant, which is equal to the ferromagnetic spin ground state with $g\left(S_{\mathrm{Ni}}+S_{\mathrm{Cr}}\right)=2 \times(1+3 / 2)=5$ $N \mu_{\mathrm{B}}$.

To further understand the magnitude of the magnetic coupling of 1 and 2 between $\mathrm{Cr}^{\mathrm{III}}$ and divalent metal ion $\left(\mathrm{Fe}^{\mathrm{II}}\right.$, $\mathrm{Ni}^{\mathrm{II}}$ ), the $\mathrm{Cr}^{\mathrm{III}}-\mathrm{M}^{\mathrm{II}}$ magnetic couplings through the formate bridge can be estimated by using the molecular field result, $J / k_{\mathrm{B}}$ $=3 \theta /[2 Z S(S+1)]$. The values are $J_{\mathrm{CrFe}}=0.11 \mathrm{~cm}^{-1}$ for 1 and $J_{\mathrm{CrNi}}$ $=0.28 \mathrm{~cm}^{-1}$ for 2 . Here, we can see the values of $J$ are $J_{\mathrm{CrNi}}>$ $J_{\mathrm{CrFe}}$, because the magnetic orbital of $\mathrm{Cr}^{\mathrm{III}}\left(t_{2 \mathrm{~g}}\right)$ and $\mathrm{Ni}^{\mathrm{II}}\left(e_{\mathrm{g}}\right)$ ions are completely orthogonal but the ferromagnetic coupling between $\mathrm{Cr}^{\mathrm{III}}$ and $\mathrm{Fe}^{\mathrm{II}}$ ions is partly cancelled out by the overlapping magnetic orbitals of $\mathrm{Cr}^{\mathrm{III}}\left(t_{2 \mathrm{~g}}\right)$ and $\mathrm{Fe}^{\mathrm{II}}\left(t_{2 \mathrm{~g}}\right)$ ions. The coupling between the metals leads to a ferromagnetic state with $J>0$ different from the antiferromagnetic coupled sublattices, which are noncompensated and lead to a ferrimagnetic state. $^{23,24}$ Moreover, it should be noted that the ordering
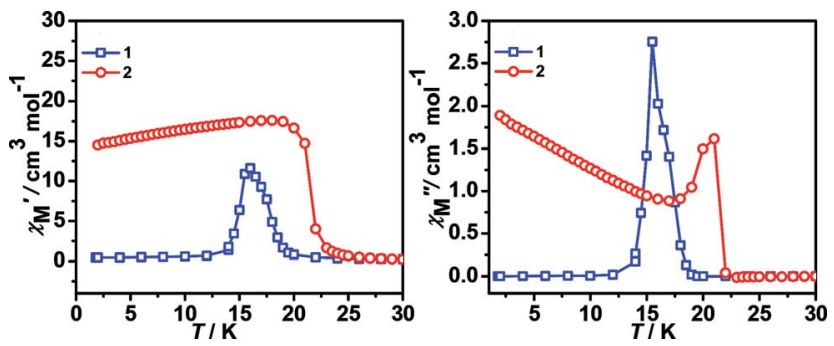

Fig. 4 ac susceptibility data at $10 \mathrm{~Hz}$ (1) and $1000 \mathrm{~Hz}(2)$ in zero static field, in (a) $\chi^{\prime}$ versus $T$ and (b) $\chi^{\prime \prime}$ versus $T$.

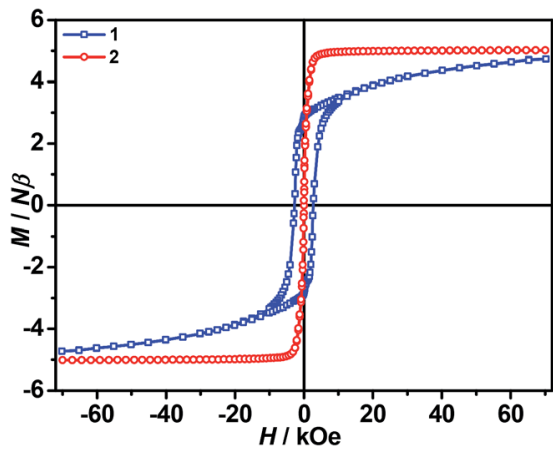

Fig. 5 Isothermal magnetization plots of 1 and 2 at $2.0 \mathrm{~K}$.

temperature of 2 containing nickel ions $(20.93 \mathrm{~K})$ is slightly higher than the ordering temperatures of some related complexes with two magnetic sublattices, which is mainly due to the slightly strong coupling interaction and is consistent with molecular field theory.

\section{Dielectric properties}

Dielectric permittivity of $\mathbf{1}$ and $\mathbf{2}$ with and without an external magnetic field were measured using the sample obtained by tableting and depicted in Fig. 6, 7, S4 and $S 5, \dagger$ where the complex dielectric constant $\varepsilon=\varepsilon^{\prime}-\mathrm{i} \varepsilon^{\prime \prime}$, and $\varepsilon^{\prime}$ and $\varepsilon^{\prime \prime}$ are the real and imaginary parts of $\varepsilon$. The model of the measurements under an applied magnetic field is shown in Fig. S6. $\dagger$ For $\mathbf{1}$ without field, the real component $\varepsilon^{\prime}$ of permittivity (Fig. 6) exhibits a step-like increase from $146 \mathrm{~K}$ to $214 \mathrm{~K}$ and the broad step-like maximum shifts to higher temperatures with increasing frequency. These phenomena are consistent with the temperature-dependent IR spectra of complex 1 (Fig. S7 $\dagger$ ) and similar to the spectra of chromium analogs, ${ }^{27}$ so can be attributed to the polarization of disordered $\mathrm{DMA}^{+}$. The changes are observed for the bands appear in the region $3060-3145 \mathrm{~cm}^{-1}$ resulting from the $\mathrm{N}-\mathrm{H}$ stretching modes and the weak bands in the $1431-1469 \mathrm{~cm}^{-1}$ range from the $\delta\left(\mathrm{CH}_{3}\right)$ modes. ${ }^{31,48}$ From 20 $\mathrm{kHz}$ to $1 \mathrm{MHz}$, the characteristic relaxor behavior of the dielectric permittivity can be observed with a relaxation of

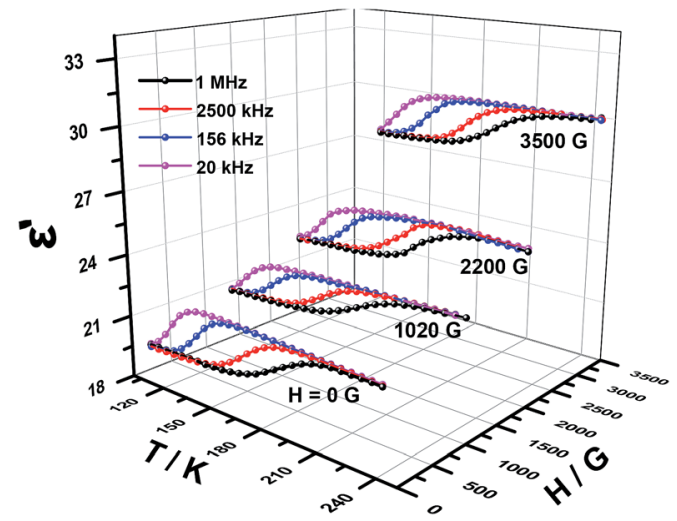

Fig. 6 Temperature dependence of the real $\varepsilon^{\prime}$ part of the dielectric permittivity for 1 under different magnetic field. 


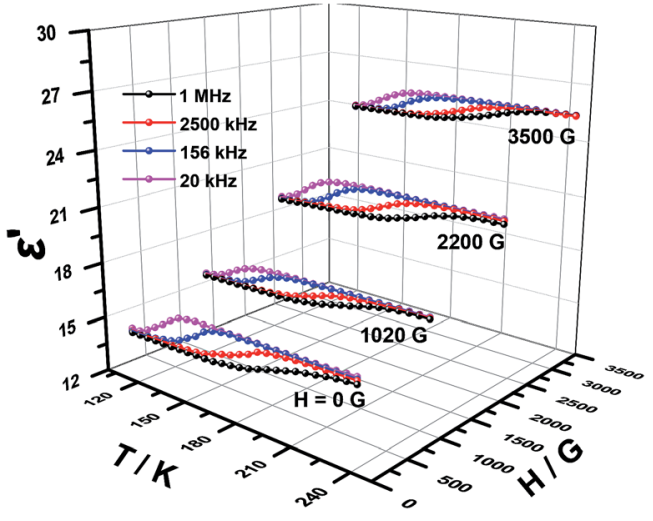

Fig. 7 Temperature dependence of the real $\varepsilon^{\prime}$ part of the dielectric permittivity for 2 under different magnetic field.

approximately $70 \mathrm{~K}$. Applied a magnetic field, the shape of the $\varepsilon^{\prime}$ curves is not changed. Interestingly, the dielectric constant values are totally increased. The stronger the magnetic field, the larger the dielectric constant values (Fig. 6). We have searched for the interpretation of this kind of behavior in reference, but there is no any report about it until now. ${ }^{3,49}$ In our opinion, it may be a new physical phenomenon. The mechanism should be much complicated but it still urges us to give a tentative analysis. To the best of our knowledge, the cases that the magnetic field affect charges include three possibilities, Lorenian force, slight change of structure for paramagnetic complexes and Hall effect.

A dielectric material is an electrical insulator so the electric charges cannot flow through the material when an electric field is applied. However, the electric charges can still shift from their original positions and form an electric double layer, named as polarization. During the dielectric relaxation, a displacement current produced. When a perpendicular magnetic field is applied, the moving electric charges will be strongly affected by the Lorenian force. However, we applied a parallel magnetic field to the electric field for the measurement, so the electrons within material were not affected by Lorenian force, which do not provide the contribution for the

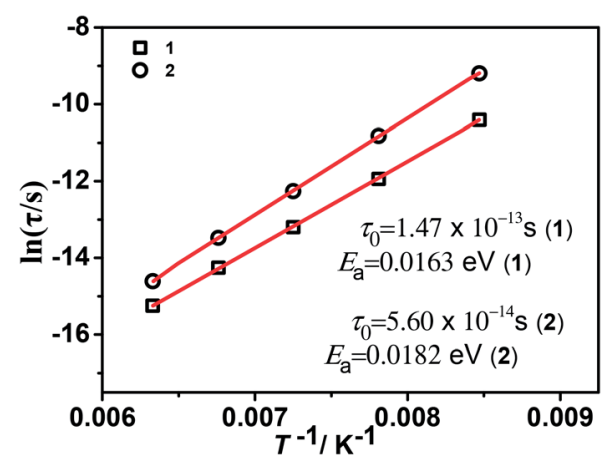

Fig. 8 Arrhenius plots of $\ln (\tau)$ vs. the inverse temperature $T^{-1}$ for 1 and 2. Red lines show the fit of data to the Arrhenius expression $\tau=\tau_{0^{-}}$ $\exp \left(E_{\mathrm{a}} / k_{\mathrm{B}} T\right)$.
Table 2 The activity energy $E_{\mathrm{a}}$ and relaxation time $\tau_{0}$ for 1 and 2

\begin{tabular}{llllll}
\hline Complex & $\tau_{0} / \mathrm{s}$ & $E_{\mathrm{a}} / \mathrm{eV}$ & Complex & $\tau_{\mathrm{o}} / \mathrm{s}$ & $E_{\mathrm{a}} / \mathrm{eV}$ \\
\hline $\mathbf{1}(0 \mathrm{G})$ & $1.47 \times 10^{-13}$ & 0.0163 & $\mathbf{1}(1020 \mathrm{G})$ & $1.84 \times 10^{-13}$ & 0.0157 \\
$\mathbf{2}(0 \mathrm{G})$ & $5.60 \times 10^{-14}$ & 0.0182 & $2(1020 \mathrm{G})$ & $7.90 \times 10^{-14}$ & 0.0178 \\
$\mathbf{1}(200 \mathrm{G})$ & $2.48 \times 10^{-13}$ & 0.0158 & $\mathbf{1}(3500 \mathrm{G})$ & $4.00 \times 10^{-13}$ & 0.0154 \\
$2(2200 \mathrm{G})$ & $1.05 \times 10^{-13}$ & 0.0176 & $2(3500 \mathrm{G})$ & $2.04 \times 10^{-13}$ & 0.0169
\end{tabular}

enrichment of charges in the electric double layer. Except the electrons within material, the space charges can usually increase the ferroelectric polarization or dielectric constants and are influenced by magnetic field. The space charge depends on the non-homogeneous media with such as crystal boundary, phase boundary, lattice distortion, and so on. But, the space charge appears in the low-frequency region, which is inconsistent with the results in Fig. 6 and 7. We cannot figure out the relation between space charge and magnetic field, namely, the magnetic field cannot increase the number of space charge.

The second reason is that the paramagnetic ions may shift under magnetic field. Complex 1 shows a quite rigid 3D structure and the applied field is not strong enough. We exclude this possibility in this experimental and it is regrettable that there is no such instrument at present internationally for measuring the single crystal structure under a magnetic field.

The third one is Hall effect, which is a phenomenon that electric current of materials is strongly related to the external magnetic field. Perpendicular to both directions of current and magnetic field, the Hall current will produce and possibly enriches the electric charge in its perpendicular direction. Similarly, we did not apply two perpendicular electric and magnetic fields. However, we noted that the applied magnetic field is very low and not uniform, which may leads to a component of magnetic lines of force perpendicular to the current direction further increase the enrichment of electric charge. According to our analyses, it will be a challenging work for illuminating above behavior. The corresponding investigations are in progress in our group on the factors about magnitude and direction of magnetic field.

$$
\begin{gathered}
\varepsilon=\varepsilon_{\infty}+\frac{\varepsilon_{\mathrm{s}}-\varepsilon_{\infty}}{1+(\mathrm{i} \omega \tau)^{\alpha}} \\
\varepsilon^{\prime}=\varepsilon_{\infty}+\frac{\left(\varepsilon_{\mathrm{s}}-\varepsilon_{\infty}\right)\left(1+\cos \frac{\alpha \pi}{2} \omega^{\alpha} \tau^{\alpha}\right)}{1+2 \cos \frac{\alpha \pi}{2} \omega^{\alpha} \tau^{\alpha}+\omega^{2 \alpha} \tau^{2 \alpha}} \\
\varepsilon^{\prime \prime}=\frac{\left.\left(\varepsilon_{\mathrm{s}}-\varepsilon_{\infty}\right) \sin \frac{\alpha \pi}{2} \omega^{\alpha} \tau^{\alpha}\right)}{1+2 \cos \frac{\alpha \pi}{2} \omega^{\alpha} \tau^{\alpha}+\omega^{2 \alpha} \tau^{2 \alpha}}
\end{gathered}
$$

For 2, the similar dielectric response (Fig. 7) was observed with the step-like increase from $149 \mathrm{~K}$ to $223 \mathrm{~K}$ and the relaxation of $75 \mathrm{~K}$. Also similarly, an external magnetic field induced 
the increase of the dielectric constants as shown in Fig. 7. We suggest that the phenomenon of magnetic field-induced dielectric properties may be ubiquitous in the dielectric materials but not only in multiferroics with both ferromagnet and ferroelectric.

At the same time, the frequency dependence of the imaginary permittivity has been discussed (Fig. S8 and S9†). The $\varepsilon^{\prime \prime}$ exhibits one relaxation peak characteristic of dipolar relaxation. The relaxation peaks shifted towards higher frequencies with increasing temperature. The imaginary part $\varepsilon^{\prime \prime}$ as a function of alternating-current (ac) frequency exhibits a broad peak in the high frequencies just where the $\varepsilon^{\prime}$ drops most steeply. This behavior is characteristic of a Debye-like dielectric relaxation, in which the reorientation of dipoles cannot respond to the applied ac electric field when high frequency exceeds a relaxation rate $1 / \tau$ (where $\tau$ is the relaxation time) and it can be expressed as function (1). This characteristic also can be seen in the disorder-order-type complexes, such as $\mathrm{NaNO}_{2}$ and nitric acid glycine. ${ }^{50}$

The temperature dependence of resulted relaxation times in the case of external field and no field (Fig. 8 and S10-12 $\dagger$ ) were fitted to the Arrhenius law of $\tau=\tau_{0} \exp \left(E_{\mathrm{a}} / k_{\mathrm{B}} T\right)$, the activity energy $E_{\mathrm{a}}$ and relaxation time $\tau_{0}$ are calculated to be $0.0163 \mathrm{eV}$, $1.47 \times 10^{-13} \mathrm{~s}$ and $0.0182 \mathrm{eV}, 5.60 \times 10^{-14} \mathrm{~s}$ for 1 and 2 , respectively. Under an applied magnetic field of $1020 \mathrm{G}, 2200 \mathrm{G}$ and $3500 \mathrm{G}$, the activity energy $E_{\mathrm{a}}$ and relaxation time $\tau_{0}$ for $\mathbf{1}$ and 2 are listed in the Table 2 . From the activity energy $E_{\mathrm{a}}$ and relaxation time $\tau_{0}$, we can see the relaxation of complexes 1 and 2 is similar but with the slight difference. Under a magnetic field, $E_{\mathrm{a}}$ of complexes 1 and 2 become smaller and $\tau_{0}$ become longer. The stronger the magnetic field, the lower the activation energy and the longer the relaxation time, which shows that an applied magnetic field has a certain effect on the relaxation behavior of the complexes. The relaxational mechanisms can be justified by the information of $\varepsilon^{\prime \prime}\left(\varepsilon^{\prime}\right)$ data (Fig. S13 $\dagger$ ) and the relaxational process is consistent with characteristic behavior of the dielectric permittivity in Fig. 6 and 7. The above results indicate that the dielectric properties of the complexes are attributed to the molecular local dipole moment. The different bivalent metal ions, $\mathrm{Fe}^{\mathrm{II}}$ and $\mathrm{Ni}^{\mathrm{II}}$ in complexes $\mathbf{1}$ and 2, respectively, make the bond lengths different, $\mathrm{Fe}^{\mathrm{II}}-\mathrm{O}=2.1174 \AA$ and $\mathrm{Ni}^{\mathrm{II}}-\mathrm{O}=2.0530 \AA$. Therefore, the volume of crystal cell for 1 is larger than that for $\mathbf{2}$ and results in the dipole moment of $\mathbf{1}$ is larger, further leads to higher dielectric constant, which is consist with the result of the dielectric measurement.

\section{Conclusions}

Two metal formate frameworks of $\left[\mathrm{NH}_{2}\left(\mathrm{CH}_{3}\right)_{2}\right]$ $\left[\mathrm{Cr}^{\mathrm{III}} \mathrm{M}^{\mathrm{II}}(\mathrm{HCOO})_{6}\right][\mathrm{M}=\mathrm{Fe}(\mathbf{1})$, Ni (2)] have been successfully synthesized by introducing the trivalent chromium ion into the niccolite structure framework. The complexes crystalized in anionic metal-formate frameworks in which the anti-anti formate ligands linked the octahedrally coordinated metal ions, while the disordered $\mathrm{Me}_{2} \mathrm{NH}_{2}{ }^{+}$cations are located in the cage of the framework. Complexes 1 and 2 exhibit LRO of ferromagnetism occurred at the Curie temperatures of 15.3 (1) and $20.9 \mathrm{~K}$
(2), respectively. Complex 1 possesses a hysteresis loop with $H_{\mathrm{c}}$ / $M_{\mathrm{r}}$ being $2.77 \mathrm{kOe} / 2.83 N \mu_{\mathrm{B}}$. Dielectric measurement reveals that the dielectric constant curves show step like shapes, which can be attributed to the dynamics of $\mathrm{DMA}^{+}$cations inside the cavities. Moreover, we found that the dielectric constants of the two complexes can be increased under an external magnetic field. With the increase of magnetic field, the larger the dielectric constants. We provide three possible reasons leading to this kind of phenomenon, further research will be focused on studying the origin of the magnetic field-induced dielectric properties or the possible magnetoelectric effects.

\section{Conflicts of interest}

There are no conflicts to declare.

\section{Acknowledgements}

This work was supported by Major State Basic Research Development Program (2013CB922102), National Natural Science Foundation of China (21571097 and 91622115) and a Project Funded by the Priority Academic Program Development of Jiangsu Higher Education Institutions.

\section{Notes and references}

1 P. Jain, N. S. Dalal, B. H. Toby, H. W. Kroto and A. K. Cheetham, J. Am. Chem. Soc., 2008, 130, 10450.

2 P. Jain, V. Ramachandran, R. J. Clark, H.-D. Zhou, B. H. Toby, N. S. Dalal, H. W. Kroto and A. K. Cheetham, J. Am. Chem. Soc., 2009, 131, 13625.

3 H.-B. Cui, Z.-M. Wang, K. Takahashi, Y. Okano, H. Kobayashi and A. Kobayashi, J. Am. Chem. Soc., 2006, 128, 15074.

4 M. Maczka, A. Pietraszko, B. Macalik and K. Hermanowicz, Inorg. Chem., 2014, 53, 787.

5 Z.-M. Wang, K.-L. Hu, S. Gao and H. Kobayashi, Adv. Mater., 2010, 22, 1526.

6 G.-C. Xu, X.-M. Ma, L. Zhang, Z.-M. Wang and S. Gao, J. Am. Chem. Soc., 2010, 132, 9588.

7 W. Zhang, H.-Y. Ye, H.-L. Cai, J.-Z. Ge, R.-G. Xiong and S.-P. D. Huang, J. Am. Chem. Soc., 2010, 132, 7300.

8 Y.-Z. Tang, Y.-M. Yu, J.-B. Xiong, Y.-H. Tan and H.-R. Wen, J. Am. Chem. Soc., 2015, 137, 13345.

9 D.-W. Fu, W. Zhang, H.-L. Cai, Y. Zhang, J.-Z. Ge, R.-G. Xiong and S.-P. D. Huang, J. Am. Chem. Soc., 2011, 133, 12780.

10 T. Hang, W. Zhang, H.-Y. Ye and R.-G. Xiong, Chem. Soc. Rev., 2011, 40, 3577.

11 W. Zhang, H.-Y. Ye and R.-G. Xiong, Coord. Chem. Rev., 2009, 253, 2980.

12 M. Maczka, A. Gagor, M. Ptak, W. Paraguassu, T. A. da Sliva, A. Sieradzki and A. Pikul, Chem. Mater., 2017, 29, 2264.

13 Y. Tian, S.-P. Shen, J.-Z. Cong, L.-Q. Yan, S.-G. Wang and Y. Sun, J. Am. Chem. Soc., 2016, 138, 782.

14 K.-L. Hu, M. Kurmoo, Z. Wang and S. Gao, Eur. J. Inorg. Chem., 2009, 15, 12050.

15 M.-Y. Li, M. Kurmoo, Z.-M. Wang and S. Gao, Chem.-Asian J., 2011, 6, 3084 . 
16 B. Liu, R. Shang, K.-L. Hu, Z.-M. Wang and S. Gao, Inorg. Chem., 2012, 51, 13363.

17 J.-P. Zhao, B.-W. Hu, F. Lloret, J. Tao, Q. Yang, X.-F. Zhang and X.-H. Bu, Inorg. Chem., 2010, 49, 10390.

18 M. Maczka, A. Gagor, B. Macalik, A. Pikul, M. Ptak and J. Hanuza, Inorg. Chem., 2014, 53, 457.

19 N. Abhyankar, J. J. Kweon, M. Orio, S. Bertaina, M. Lee, E. S. Choi, R. Q. Fu and N. S. Dalal, J. Phys. Chem. C, 2017, 121, 6314.

20 G. Kieslich, A. C. Forse, S. Sun, K. T. Butler, S. Kumagai, Y. Wu, M. R. Warren, A. Walsh, C. P. Grey and A. K. Cheetham, Chem. Mater., 2016, 28, 312.

21 N. L. Evans, P. M. M. Thygesen, H. L. B. Bostrom, E. M. Reynolds, I. E. Collings, A. E. Phillips and A. L. Goodwin, J. Am. Chem. Soc., 2016, 138, 9393.

22 D.-W. Fu, W. Zhang, H.-L. Cai, Y. Zhang, J.-Z. Ge, R.-G. Xiong, S.-P. D. Huang and T. Nakamura, Angew. Chem., Int. Ed., 2011, 50, 11947.

23 K. S. Hagen, S. G. Naik, B. H. Huynh, A. Masello and G. J. Christou, J. Am. Chem. Soc., 2009, 131, 7516.

24 Y.-Q. Tian, S.-Y. Yao, Y.-J. Guo, Y. Song and G. Zhang, Chin. J. Inorg. Chem., 2010, 26, 385.

25 L. C. Gomez-Aguirre, B. Pato-Doldan, J. Mira, S. CastroGarcia, M. A. Senaris-Rodriguez, M. Sanchez-Andujar, J. Singleton and V. S. Zapf, J. Am. Chem. Soc., 2016, 138, 1122.

26 G.-C. Xu, W. Zhang, X.-M. Ma, Y.-H. Chen, L. Zhang, H.-L. Cai, Z.-M. Wang, R.-G. Xiong and S. Gao, J. Am. Chem. Soc., 2011, 133, 14948.

27 M. Maczka, A. Pietraszko, A. Pikul and K. Hermanowicz, J. Solid State Chem., 2016, 233, 455.

28 J.-P. Zhao, S.-D. Han, X. Jiang, S.-J. Liu, R. Zhao, Z. Chang and X.-H. Bu, Chem. Commun., 2015, 51, 8288.

29 L. Mazzuca, L. Canadillas-Delgado, J. A. RodriguezVelamazan, O. Fabelo, M. Scarrozza, A. Stroppa, S. Picozzi, J.-P. Zhao, X.-H. Bu and J. Rodriguez-Carvajal, Inorg. Chem., 2017, 56, 197.

30 A. Ciupa, M. Maczka, A. Gagor, A. Sieradzki, J. Trzmiel, A. Pikul and M. Ptak, Dalton Trans., 2015, 44, 8846.

31 A. Sieradzki, S. Pawlus, S. N. Tripathy, A. Gagor, A. Ciupa, M. Maczka and M. Paluch, Phys. Chem. Chem. Phys., 2016, 18, 8462 .
32 M. Maczka, A. Ciupa, A. Gagor, A. Sieradzki, A. Pikul and M. Ptak, J. Mater. Chem. C, 2016, 4, 1186.

33 J.-P. Zhao, J. Xu, S.-D. Han, Q.-L. Wang and X.-H. Bu, Adv. Mater., 2017, 29, 1606966.

34 D. Di Sante, A. Stroppa, P. Jain and S. Picozzi, J. Am. Chem. Soc., 2013, 135, 18126.

35 M. Ptak, A. Gagor, A. Sieradzki, B. Bondzior, P. Deren, A. Ciupa, M. Trzebiatowska and M. Maczka, Phys. Chem. Chem. Phys., 2017, 19, 12156.

36 B. Saparov and D. B. Mitzi, Chem. Rev., 2016, 116, 4558.

37 R. Shang, S. Chen, K.-L. Hu, B.-W. Wang, Z.-M. Wang and S. Gao, Chem.-Eur. J., 2016, 22, 6199.

38 M. Maczka, A. Ciupa, A. Gagor, A. Sieradzki, A. Pikul, B. Macalik and M. Drozd, Inorg. Chem., 2014, 53, 5260.

39 Y.-Z. Tang, X.-F. Huang, Y.-M. Song, P.-W. Hong Chan and R.-G. Xiong, Inorg. Chem., 2006, 45, 4868.

40 Q. Ye, Y.-M. Song, G.-X. Wang, K. Chen, D.-W. Fu, P.-W. Hong Chan, J.-S. Zhu, S.-P. D. Huang and R.-G. Xiong, J. Am. Chem. Soc., 2006, 128, 6554.

41 G. M. Sheldrick, Acta Crystallogr., Sect. A: Found. Adv., 2015, $71,3$.

42 G. M. Sheldrick, Acta Crystallogr., Sect. C: Cryst. Struct. Commun., 2015, 71, 3.

43 L. Krause, R. Herbst-Irmer, G. M. Sheldrick and D. Stalke, J. Appl. Crystallogr., 2015, 48, 3.

44 S. Kuze, D. d. Boulay, N. Ishizawa, N. Kodama, M. Yamaga and B. Henderson, J. Solid State Chem., 2004, 177, 3505.

45 D. Altermatt and I. D. Brown, Acta Crystallogr., Sect. B: Struct. Sci., 1985, 41, 244.

46 D. Brown, Chem. Rev., 2009, 109, 6858.

47 S. Chen, R. Shang, K.-L. Hu, Z.-M. Wang and S. Gao, Inorg. Chem. Front., 2014, 1, 83.

48 M. Ptak, M. Mączka, A. Gągor, A. Sieradzki, A. Stroppa, D. D. Sante, J. M. Perez-Mato and L. Macalik, Dalton Trans., 2016, 46, 2574.

49 J.-B. Guo, L.-H. Chen, D. Li, H.-X. Zhao, X.-W. Dong, L.-S. Long, R.-B. Huang and L.-S. Zheng, Appl. Phys. Lett., 2017, 110, 192902.

50 P. Ravindran, A. Delin, B. Johansson, O. Eriksson and J. M. Wills, Phys. Rev. B: Condens. Matter Mater. Phys., 1999, 59, 1776. 